\title{
Westphal, Siegrid, Schmidt-Voges, Inken, Baumann, Anette, Venus und Vulcanus. Ehen und ihre Konflikte in der Frühen Neuzeit
}

\section{Christophe Duhamelle}

\section{OpenEdition}

1 Journals

\section{Édition électronique}

URL : http://journals.openedition.org/ifha/6525

DOI : $10.4000 /$ ifha. 6525

ISSN : 2198-8943

\section{Éditeur}

IFRA - Institut franco-allemand (sciences historiques et sociales)

\section{Référence électronique}

Christophe Duhamelle, « Westphal, Siegrid, Schmidt-Voges, Inken, Baumann, Anette, Venus und Vulcanus. Ehen und ihre Konflikte in der Frühen Neuzeit », Revue de I'IFHA [En ligne], Date de recension, mis en ligne le 01 janvier 2012, consulté le 22 septembre 2020. URL : http://journals.openedition.org/ ifha/6525 ; DOl : https://doi.org/10.4000/ifha.6525

Ce document a été généré automatiquement le 22 septembre 2020.

(CIFHA 


\title{
Westphal, Siegrid, Schmidt-Voges, Inken, Baumann, Anette, Venus und Vulcanus. Ehen und ihre Konflikte in der Frühen Neuzeit
}

\author{
Christophe Duhamelle
}

1 Le travail des trois auteures est consacré au mariage et à ses conflits. Où ? Le SaintEmpire serait ici « pars pro toto » (p. 12) et quelques illustrations - Hogarth, Brueghel, Clouet - pourraient laisser croire à une synthèse européenne. La lecture montre vite que, pour l'essentiel, c'est l'aire germanique qui est saisie au travers, surtout, de cas portés devant les tribunaux ; cette restriction n'est en soi pas un problème à condition d'être assumée et contextualisée. L'ouvrage procède selon un plan limpide. Les auteures ont réparti entre elles les étapes chronologiques de la vie conjugale : ce qui la prépare et la noue (A.B.) ; les accidents qui la parsèment (I.S.-V.) ; ce qui l'achève (S.W.) - avec une place peut-être démesurée accordée à la séparation qui aux Temps modernes ne constitue tout de même pas le cas modal. Les trois parties présentent le cadre normatif de la vie conjugale, puis la pratique appréhendée principalement au travers d'exemples de procès, dits exemplaires à défaut de bien savoir ce qu'ils exemplifient. Quelques excursions rares mais bienvenues vers d'autres champs (p. 109-116 sur les médias de diffusion des normes conjugales) agrémentent ce schéma qui toutefois produit souvent une impression de monotonie : il n'était peut-être pas nécessaire de revenir plusieurs fois sur les conceptions de Luther en matière de mariage et il faudra un jour se demander de quoi les citations du dictionnaire Zedler, manne historienne en ces temps de recherche connectée, sont révélatrices.

2 Riche florilège de cas, l'ouvrage ne parvient qu'imparfaitement à faire apparaître une ligne directrice. Les différences sociales servent ici avant tout de moyen de classement. Et les conflits, traités un peu trop pour eux-mêmes, sont scandés selon une typologie qui relève davantage d'une manière de casuistique judiciaire que d'un ancrage dans le substrat démographique, culturel et sociologique qui pourrait leur donner un sens plus 
acéré. Il est vrai que la bibliographie, bien que riche de quelque 290 titres, révèle une conception tronquée des recherches sur le mariage. On s'étonne de ne pas y rencontrer, pour ne prendre à notre tour que quelques exemples, l'ouvrage pionnier d'Arthur Imhof, les fortes monographies de Heinz Reif ou Gregory Pedlow essentielles pour la noblesse, et pour les mondes paysans celles de Jürgen Schlumbohm ou David Sabean, dont les analyses passionnantes sur le vocabulaire du conflit conjugal (Property, production and family in Neckarhausen, 1990, p. 139-146) manquent cruellement à la lecture du passage consacré au même thème (p. 148-150). Espérons que ne sera pas mise au débit d'un nationalisme étroit la constatation attristée que la bibliographie ne comporte que 3 titres en français : il s'agit plutôt d'y voir le signe d'une indifférence envers les apports de la démographie historique et d'une certaine anthropologie pour la compréhension du mariage ancien. Il est permis de penser que l'étude des conflits conjugaux perd une grande partie de sa force si elle ne s'inscrit pas dans ces acquis de la recherche et qu'un ouvrage sur ce thème " flotte » lorsqu'il n'ente pas les conflits sur la précision de leur contexte et lorsqu'il refuse décidément de présenter la moindre statistique - la question de l'âge au mariage, dont il n'est peut-être pas utile de rappeler l'importance, est ainsi expédiée en un exemple sommaire (p. 33) et, pour les populations juives, une « moyenne » dont la précision laisse pantois (« l'âge moyen au mariage se situait chez les filles entre la 12ème et la 18ème année et chez les garçons entre la 15ème et la 18ème année ", p. 47). Quant au lien entre les noces et les naissances, abordé en deux pages et quelques conflits (p. 136-137), il aurait pu permettre de se demander si les conflits liés au mariage sont tous nécessairement des conflits conjugaux.

On aura compris que cet ouvrage n'emporte pas entièrement l'adhésion du recenseur qui veut bien avouer que sa vision est faussée par un ballast historiographique dont il ne parvient pas entièrement à admettre l'inanité. Il n'en reste pas moins que les auteures ne répondent pas de manière pleinement satisfaisante à la question la plus aiguë que pose le livre : celle de sa nécessité.

Christophe Duhamelle (EHESS) 